\title{
Pericentric Inversion of Chromosome No. 13 in a Large Family Leading to Duplication Deficiency Causing Congenital Malformations in Three Individuals
}

\section{HALLA HAUKSDÓTTIR,* SÆVAR HALLDÓRSSON,† ÓLAFUR JENSSON,* MARGARETA MIKKELSEN, $\ddagger$ and ALAN MCDERMOTT**}

Few examples of pericentric inversion in human autosomes have been reported up to the present time. Three examples of such chromosome abnormalities were connected with the D-group chromosomes according to Parrington and Edwards (1971), who were the first to describe a case that had many of the findings of Patau's syndrome and a

Received 4 April 1972.

* Cytogenetics Laboratory, Genetics Committee of the University of Iceland, Department of Pathology, Reykjavik, Iceland.

† Paediatric Department, University Hospital Iceland; Home for the Mentally Retarded, Kópavogur; Paediatric Department, St Joseph's Hospital, Reykjavik, Iceland.

‡ John F. Kennedy Instituttet, G1. Landevej 7-9, Copenhagen, Denmark.

** Faculty of Medicine, University of Calgary, Calgary 42, Alberta, Canada. duplication deficiency derived from a maternal Dgroup pericentric inversion.

A female with secondary amenorrhoea, webbed neck, and kyphosis and a chromosome D pericentric inversion was reported by Cohen, Capraro, and Takagi (1966/1967). Crandall and Sparkes (1970) described a pericentric inversion in 9 members of a family, all of whom were phenotypically normal.

In the family presented here (Fig. 1) 3 children had congenital malformations. Chromosome analysis could only be performed in 2 of them, both had abnormal karyotypes. Chromosome studies in the family showed that 14 phenotypically normal individuals had an abnormal karyotype which differed from that found in the 2 abnormal children.

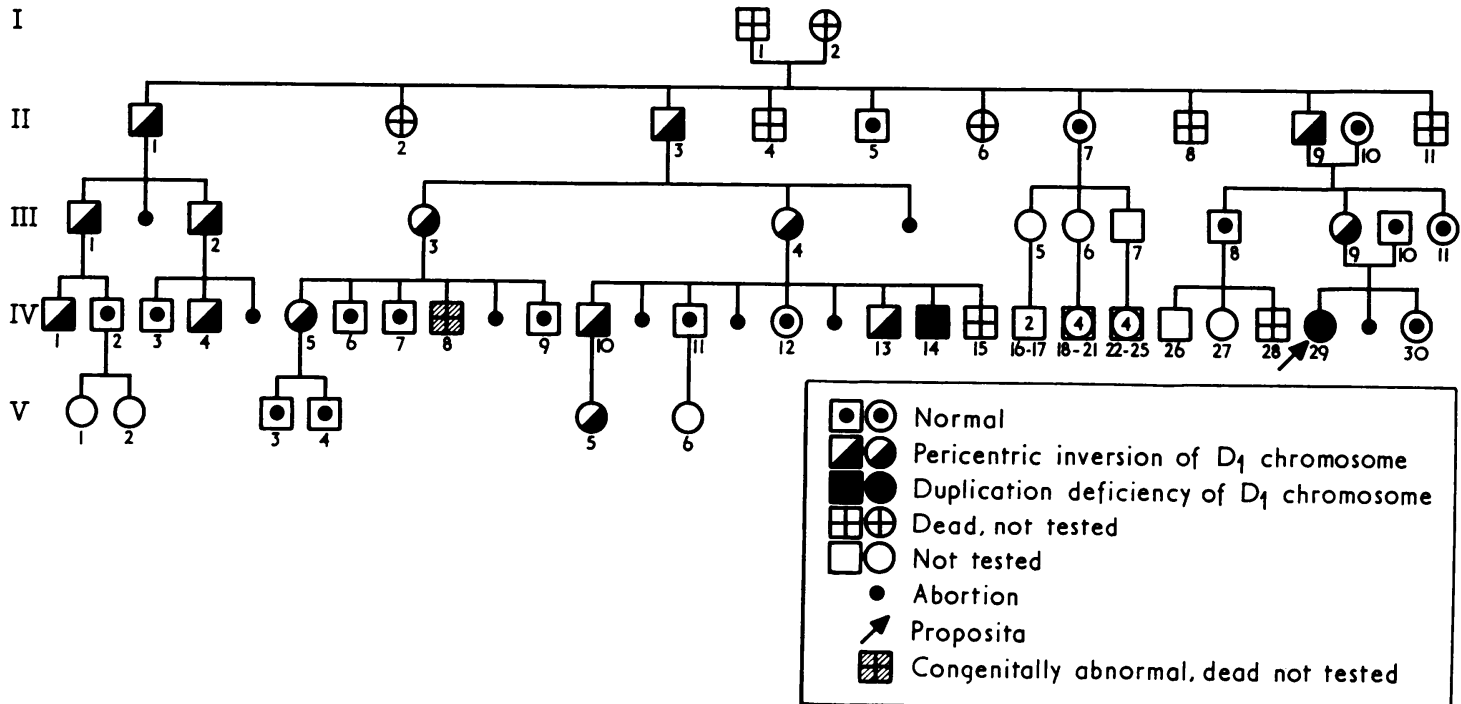

FIG. 1. Pedigree of the family. 

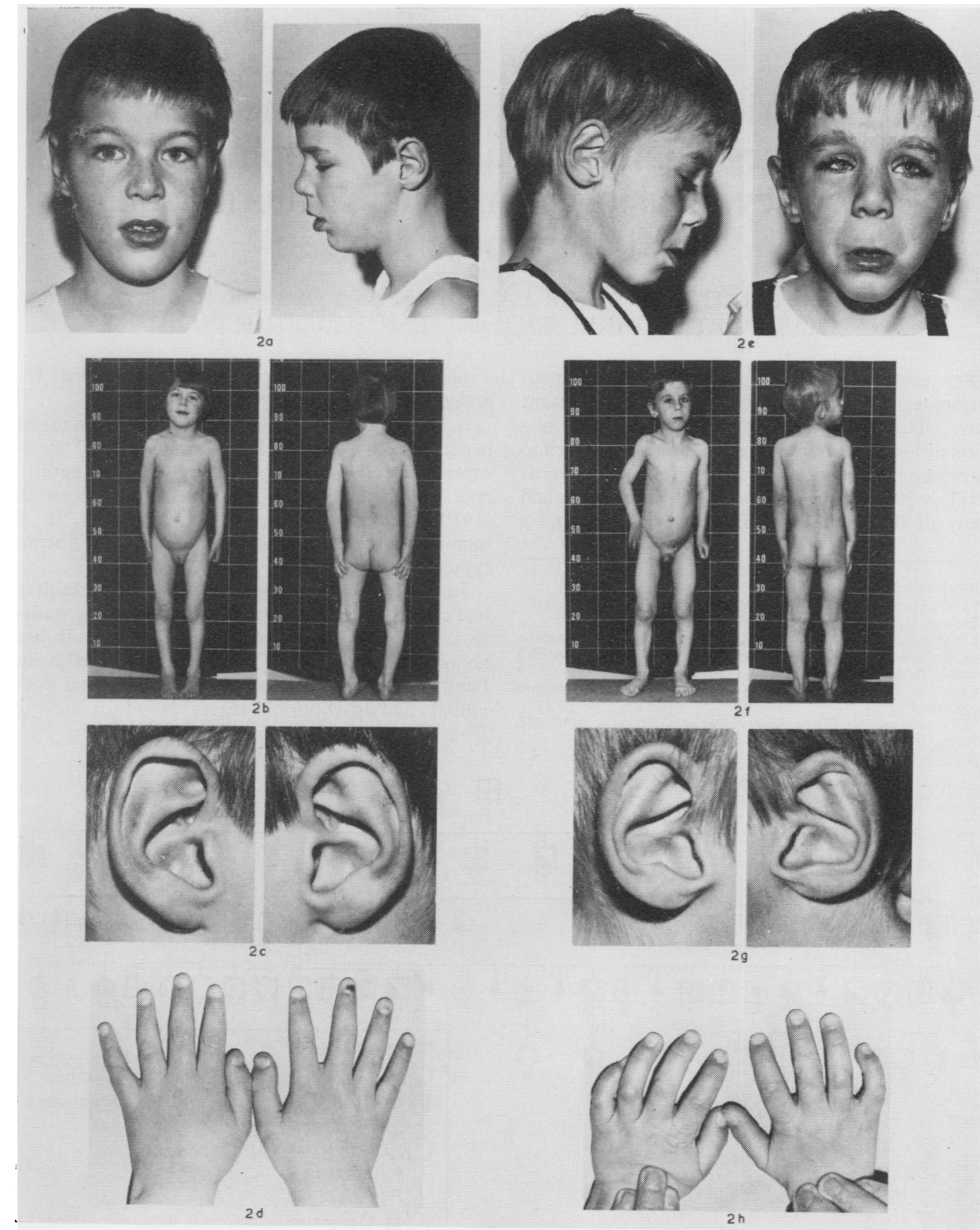
Fig. 2. The proposita (case 1$)$ at 8 years $(2 \mathrm{a})$ and 4 years $(2 \mathrm{~b})$; her ears $(2 \mathrm{c})$ and hands $(2 \mathrm{~d})$ are also shown. Case 2 is shown on the
right at $4 \frac{1}{2}$ years ( $2 \mathrm{e}$ and $\left.2 \mathrm{f}\right)$; his ears $(2 \mathrm{~g})$ and hands $(2 \mathrm{~h})$ are also shown. 


\section{Case Histories}

Case 1 (IV.29). The proposita, a 5-year-old girl, was referred because of delayed mental development. She was the 1st child of a 24-year-old woman, who had one miscarriage when 2 months pregnant. Labour started at 38 weeks and delivery was normal. At birth she had a small extra digit on the ulnar side of the left hand. There was also a capillary haemangioma on the forehead and at the nape of the neck. She was an extremely 'fussy' and irritable infant. She walked at 11 months, talked between 3 and 4 years and was toilet-trained at $2 \frac{1}{2}$ years.

In 1966 she was hospitalized, and the only laboratory abnormalities were elevation of 17-ketosteroids in the urine (2-2.5 $\mathrm{mg}$ in 24 hours) and an IVP showed abnormal bilateral dilation of pelvis and calyces. No other abnormalities were found. At 4 years 2 months she was referred to the Paediatric Department of the University Hospital Copenhagen, with signs of early breast development, tall stature (height 97th centile), and elevated 17ketosteroids. The urinary 17 -ketosteroids were repeated but were found normal. Bone age was considered slightly advanced. Pneumoencephalography and other studies showed no abnormality. No diagnosis was made.

Physical Examination. At $6 \frac{1}{2}$ years in 1966 her height was $123 \mathrm{~cm}$ (90th centile) and her weight $25.5 \mathrm{~kg}$. Head circumference was $51 \mathrm{~cm}$. Several physical abnormalities were apparent (see Fig. 2 and Table I). The eyelashes, especially the upper ones, were unusually long and numerous and markedly curled. She had alternating divergent strabismus of divergens excess type. The

TABLE I

THE THREE CASES WITH CONGENITAL ABNORMALITIES

\begin{tabular}{|c|c|c|c|}
\hline & Case 1 & Case 2 & Case 3 \\
\hline $\begin{array}{l}\text { Cranio-facial } \\
\text { Hypertrichosis of the eyelashes } \\
\text { Strabismus } \\
\text { Optic atrophy } \\
\text { Peculiar ears } \\
\text { Long upper lip } \\
\text { Mild micrognathia } \\
\text { High and narrow palate } \\
\text { Poor teeth } \\
\text { Capillary haemangioma of forehead } \\
\text { and neck }\end{array}$ & $\begin{array}{l}+ \\
+ \\
+ \\
+ \\
+ \\
+ \\
+ \\
+ \\
+\end{array}$ & $\begin{array}{l}+ \\
+ \\
0 \\
+ \\
+ \\
+ \\
+ \\
+ \\
+\end{array}$ & $\begin{array}{l}? \\
? \\
? \\
? \\
? \\
? \\
? \\
? \\
0\end{array}$ \\
\hline $\begin{array}{l}\text { Genitalia } \\
\text { Large labia majora } \\
\text { Cryptorchidism }\end{array}$ & + & + & + \\
\hline $\begin{array}{l}\text { Extremities } \\
\text { Polydactyly } \\
\text { Abnormal shape of thighs } \\
\text { Large joints } \\
\text { Deformed thumbs } \\
\text { Acrocyanosis of hands and feet }\end{array}$ & $\begin{array}{l}+ \\
+ \\
+ \\
+ \\
+\end{array}$ & $\begin{array}{l}+ \\
+ \\
+ \\
+ \\
+\end{array}$ & $\begin{array}{l}+ \\
? \\
? \\
? \\
?\end{array}$ \\
\hline $\begin{array}{l}\text { Miscellaneous } \\
\text { Irritability in infancy } \\
\text { Excessive length } \\
\text { Inguinal hernia } \\
\text { Pectus excavatum } \\
\text { Infantile mamma hyperplasia } \\
\text { Saccral dimple } \\
\text { Congenital heart disease } \\
\text { Mental retardation } \\
\text { Renal anomalies }\end{array}$ & $\begin{array}{l}+ \\
+ \\
0 \\
+ \\
+ \\
+ \\
0 \\
+ \\
+\end{array}$ & $\begin{array}{l}+ \\
0 \\
+ \\
0 \\
+ \\
+ \\
+ \\
+ \\
+\end{array}$ & $\begin{array}{l}+ \\
+ \\
+ \\
? \\
? \\
+ \\
+ \\
?\end{array}$ \\
\hline
\end{tabular}

optic discs were pale. The upper lip was long and flat and the palate high and narrow. The teeth were in poor condition. There was slight micrognathia. The ears had a prominent antihelix with an extra ridge of cartilage beneath. There were no lobes. She had pectus excavatum and slight breast development. The labia majora were large but otherwise the genitalia looked normal. There was a rather poor muscular development of the extremities most marked distally. All joints were large, especially the wrists, ankles, and knees. The hands and feet were cold and mottled. There was ulnar deviation of the distal phalanges of the thumbs of both hands. Inspected from behind the shape of her thighs appeared peculiar; the upper part of the buttockfold was asymmetrical and deviated to the right terminating in a dimple. She was hyperactive and restless and her attention span was very short. Psychological testing (Terman Merrill) gave an IQ of 57. No other neurological abnormalities were found.

Case 2 (IV.14). In this family a 4 -year-old boy was discovered who was mentally retarded and had similar physical abnormalities as the proposita (see Fig. 2 and Table I) and the same chromosomal abnormality. He was the 5th child, and his mother was 38 at his birth. She had had at least 3 miscarriages but it was not known when. The pregnancy and delivery were normal. At birth he had several physical abnormalities: hexadactyly on both feet, bilateral cryptorchidism, and a right-sided inguinal hernia. The defects were repaired surgically. He had a capillary haemangioma on the forehead and at the nape of the neck and occiput. He was always quite 'fussy' and irritable as an infant. He stood up at $1 \frac{1}{2}$ years, walked at 2 years of age, and began to talk between 3 and 4 years. It soon became apparent that the boy's mental development was retarded. His behaviour has always been abnormal, characterized by hyperactivity. An IVP showed dilatation and elongation of the left renal pelvis but no other urological anomalies except diurnal enuresis were noted.

Physical Examination. At examination at 4 years 7 months (September 1970) he was seen to be a rather thin boy. His weight was $18 \mathrm{~kg}$ and height $110 \mathrm{~cm}$ (75th centile). Head circumference was $51 \mathrm{~cm}$; the forehead and the hairline were low. There was a faint capillary naevus in the occipital area. He had synophrys and the palpebral fissures seemed small because of extremely long, thickly set, and curly eyelashes. The nose was somewhat broad with slight epicanthus. The upper lip was long and flat. There was slight micrognathia. The ears were both broad and large without lobes, and slightly low set; the antihelix was very prominent and curved in a sharp angle. He had an alternating convergent strabismus. The teeth were rather poorly developed and the palate high and narrow. The chest was normally shaped. The left testis was in the scrotum but the right was only palpable in the groin. There was an ulnar deviation of the distal phalanges of the thumbs. Many joints were prominent, especially the wrists, knees, and ankles. Distally the extremities seemed thin. From behind the thighs appeared peculiar in shape although not as 
striking as in the proposita. The buttockfold was symmetrical, the upper part ending in a dimple; there were also several skin tags. During examination he was restless and his attention span was very short. Recent psychological testing showed the IQ to be slightly above 40. Except for mild hypotonia and reduction in muscle strength there were no other abnormal neurological signs.

Laboratory Examination. Routine laboratory studies were normal. Bone age was normal. He had abnormal karyotype (see below).

Case 3 (IV.8). This child, born on 14 September 1956 who died on 12 March 1957, was the 5th child of a 29-year-old mother. The pregnancy and delivery were normal. When 4 months old he was admitted to a small hospital because of irritability and fever. He had always been extremely 'fussy' and irritable, had failed to thrive, and was very thin. His parents considered his body length excessive for his age. His facial appearance was described as monkey-like (no photograph was available); the same observation had also been made about cases 1 and 2.

Physical Examination. In the medical record there was no description of his facial appearance. He was described as thin, his weight being $5880 \mathrm{~g}$, which is far below the 3rd centile (unfortunately no length measurements were available). He had marked tachycardia but no murmurs, and clinically and radiologically the heart was enlarged (films lost). He had bilateral inguinal hernia and bilateral cryptorchidism. He had hexadactyly of both hands and both feet. He was discharged and readmitted 2 weeks later in coma with a high fever $\left(42^{\circ} \mathrm{C}\right)$ and died a few hours later. The clinical diagnosis was pneumonia but no necropsy was performed.

\section{Chromosome Studies}

Chromosome analysis was performed on peripheral blood cultures prepared by the micromethod described by Edwards (1962).

All members of the family tested had karyotypes consisting of 46 chromosomes. The proposita (IV.29) had a female karyotype with one chromosome missing from the D-group, and an additional chromosome in the C-group similar in appearance to chromosome No. 10 (Fig. 3). The same chromosome abnormality was found in a relative (case 2 ; IV.14) who was also malformed.

The mother of the proposita, who appeared normal, had a female karyotype with one chromosome missing from the D-group, a normal set of C-group chromosomes, and an additional metacentric chromosome resembling a No. 16 (Fig. 4). This same abnormal chromosome was found in 13 phenotypically normal relatives (see Fig. 1) in some of whom satellites could be identified on the long arms of the extra chromosome; in most cells fuzzy ends rather than definite satellites, could be seen. In many cells this chromosome was associated with acrocentric chromosomes (Fig. 5).

Fluorescence studies were carried out after staining with mepacrine dihydrochloride (Mikkelsen, 1971).

In the proposita the abnormal C-group chromosome showed a fluorescent pattern different from the other C-group chromosomes. It had a bright fluorescent band on the distal part of its long arms as

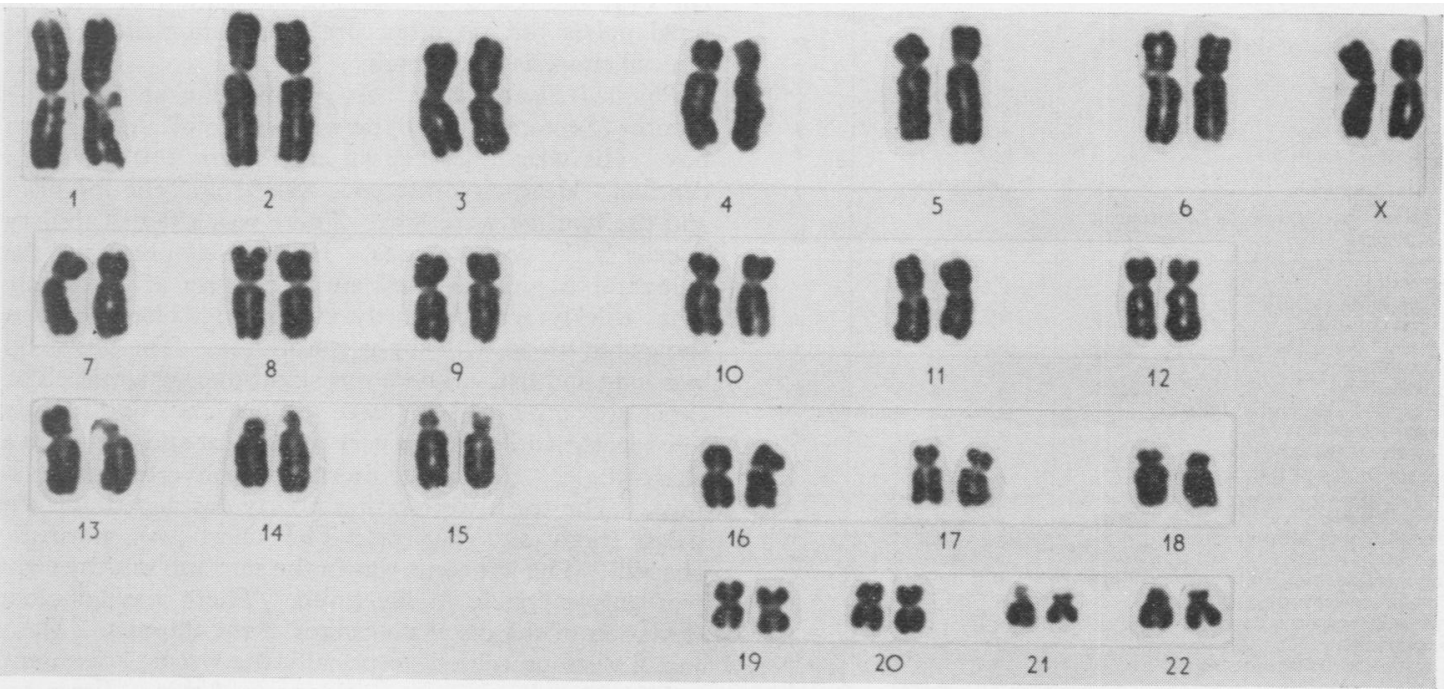

FIG. 3. Karyotype of proposita (IV.29) showing recombiant chromosome No. 13, 46,XX, rec (dup 13). 


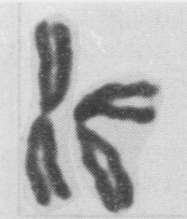

1

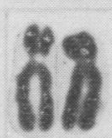

7

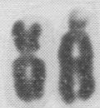

713

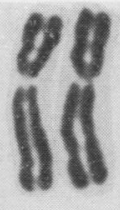

2

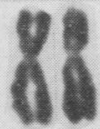

8

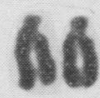

14

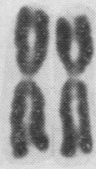

3

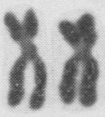

9

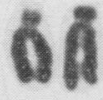

15

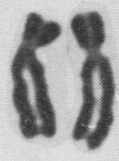

4

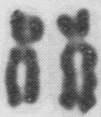

10

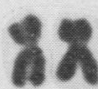

16 8x. ข้า

19

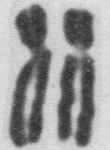

5

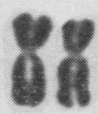

11

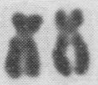

17

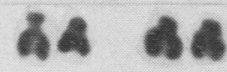

21

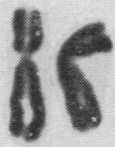

6

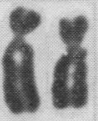

12

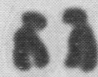

18

22

FIG. 4. Karyotype of the mother of proposita (III.9) showing pericentric inversion of chromosome No. 13, 46,XX, inv (13p + $q-$ ).
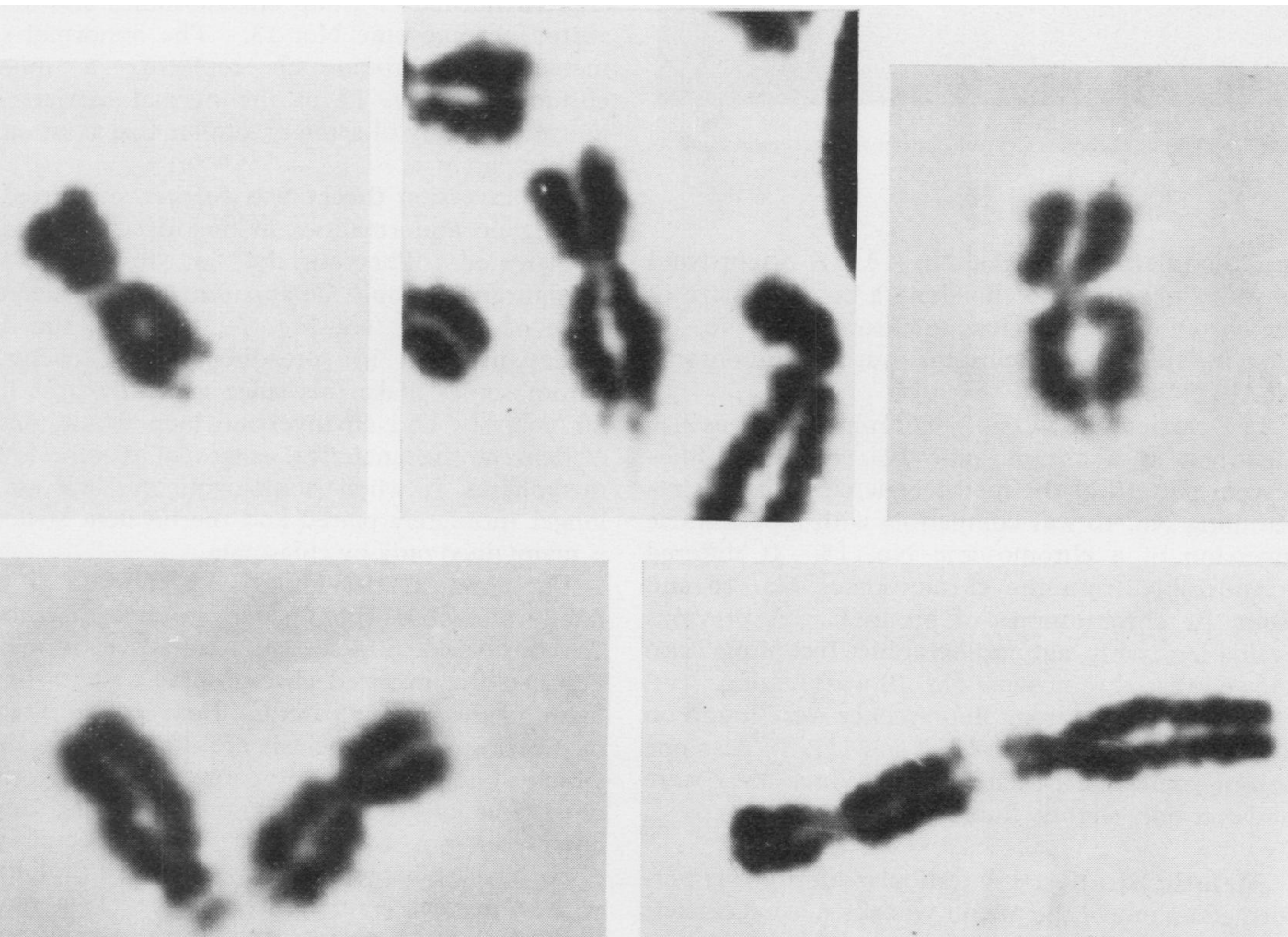

Frg. 5. The inverted chromosome No. 13, showing satellites. 


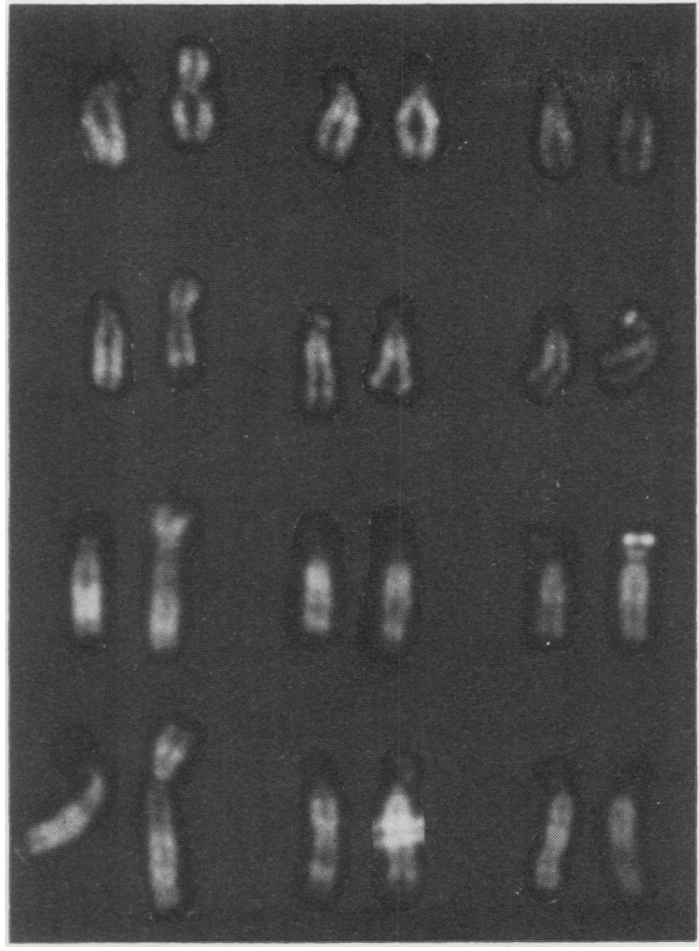

Fig. 6. D group chromosomes from 2 heterozygotes (cases 1 and 2).

the distal part of a normal No. 13. A bright band was also observed on the short arm. The size of the chromosome was close to chromosome No. 10. The missing $\mathrm{D}$ chromosome was a chromosome No. 13 (Fig. 6).

In 2 carriers the missing $\mathrm{D}$ chromosome was also identified as a chromosome No. 13. The fluorescent pattern of the metacentric chromosome resembling No. 16 was compatible with a pericentric inversion of a chromosome No. 13. It differed considerably from the chromosomes No. 16 and from the chromosomes of group C. A previous evaluation with autoradiographic technique also showed that chromosome No. 13 was missing.

Satellites with strong fluorescence were found on a chromosome No. 15 in III.3 and III.4. Also one chromosome No. 14 had large satellites, they were however only slightly fluorescing.

Meiotic Studies. A testicular biopsy was performed on one of the phenotypically normal carriers (III.2) for examination of the meiotic chromosomes, which were prepared as described by McDermott (1966/1967). Analysis of 45 suitable preparations of the diakenesis and metaphase I stages revealed normal karyotypes, consisting of 22 autosomal bivalents and a typical XY bivalent.

Genetic Marker Studies. Blood group and biochemical genetic markers listed in Table II were determined at the Galton Laboratory, University College, London. No inconsistencies were found. A girl (V.5) was found to have AB type of 6PGD while her parents had A type. However, as both father and daughter are carriers of the $D_{1}$ inversion and as this preparation had been difficult to type due to postal delays, no significance was attached to this.

\section{Discussion}

In the early phase of this study the structural changes found in the normal carriers were thought to be a C/D reciprocal translocation between a part of the long arm of a $\mathrm{C}$ chromosome and a part of the short arm of a D chromosome. This interpretation of the chromosome picture was abandoned in favour of inversion when fluorescence staining showed normal C-group chromosomes and an inverted chromosome No. 13. The abnormal submetacentric chromosome replacing a missing chromosome No. 13 in the normal carriers was morphologically of same or similar size as its single counterpart.

The inversion theory was further supported by finding no abnormalities in meiosis in the carrier investigated. Theoretically, an inversion loop configuration should be apparent at the pachytene stage of meiosis (see Fig. 7); however, the difficulties involved in spreading human pachytene chromosomes make this stage generally unsuitable for analysis, and an inversion loop would not be evident at the analytical stages of diakinesis and metaphases I, when homologous regions are no longer intimately paired and the bivalent structure is maintained only by chiasmata.

The abnormalities found in 3 children of this family, 2 of whom could be ascertained cytologically, are considered to be due to a cross-over in meiosis between the inverted chromosome and its homologue in the carrier parent. Four possible results of crossing-over at meiosis are illustrated in Fig. 7 which shows 4 types of gametes formed (single cross-over of two chromosome strands, double cross-over not considered). The expected products of these haploid strands forming a diploid cell with a normal counterpart will be (1) a normal individual; (2) a normal carrier; (3) a congenitally abnormal individual caused by duplication of the distal end of the long arm of chromosome No. 13 
TABLE II

BLOOD GROUPS AND BIOCHEMICAL GENETIC MARKERS

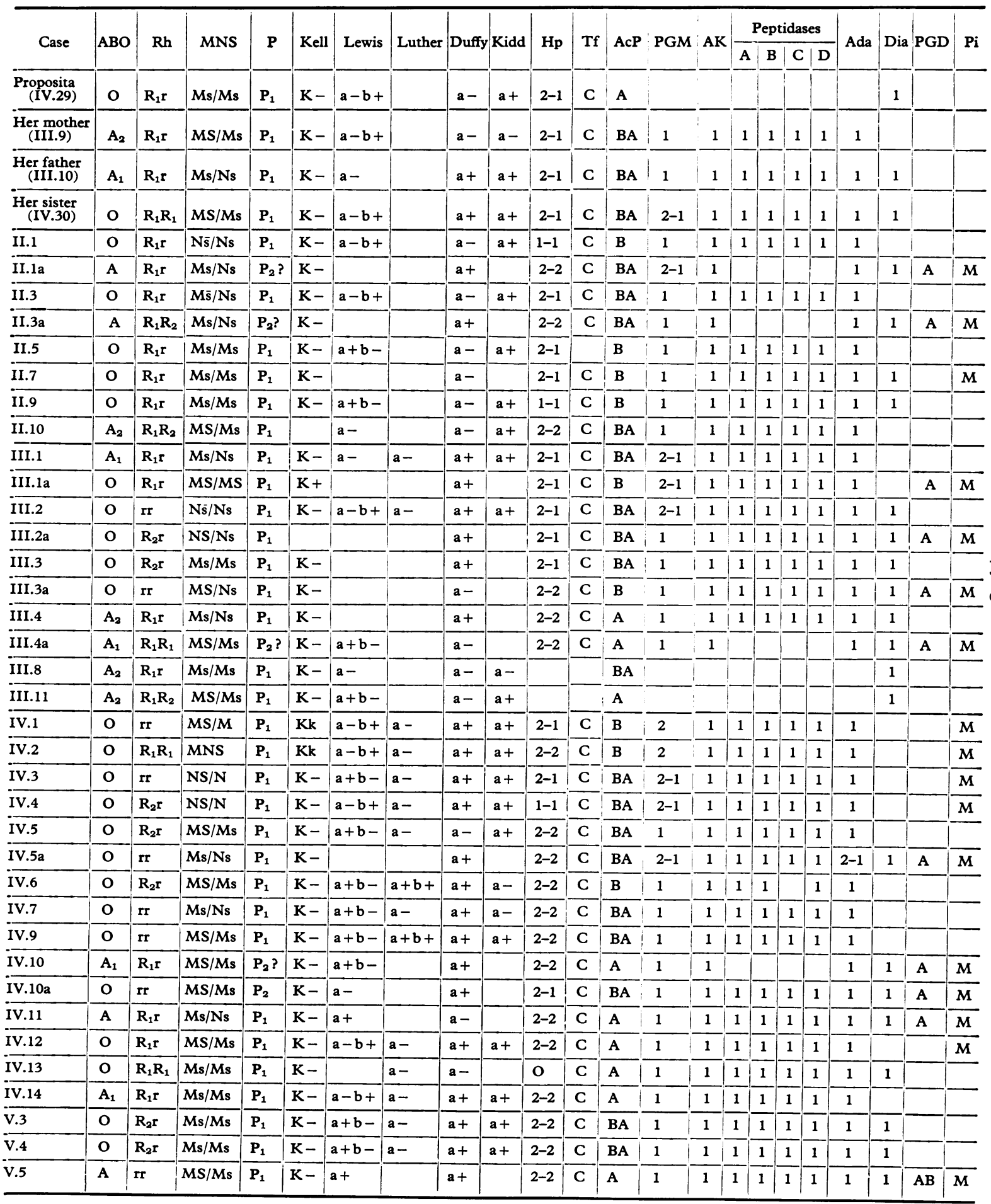




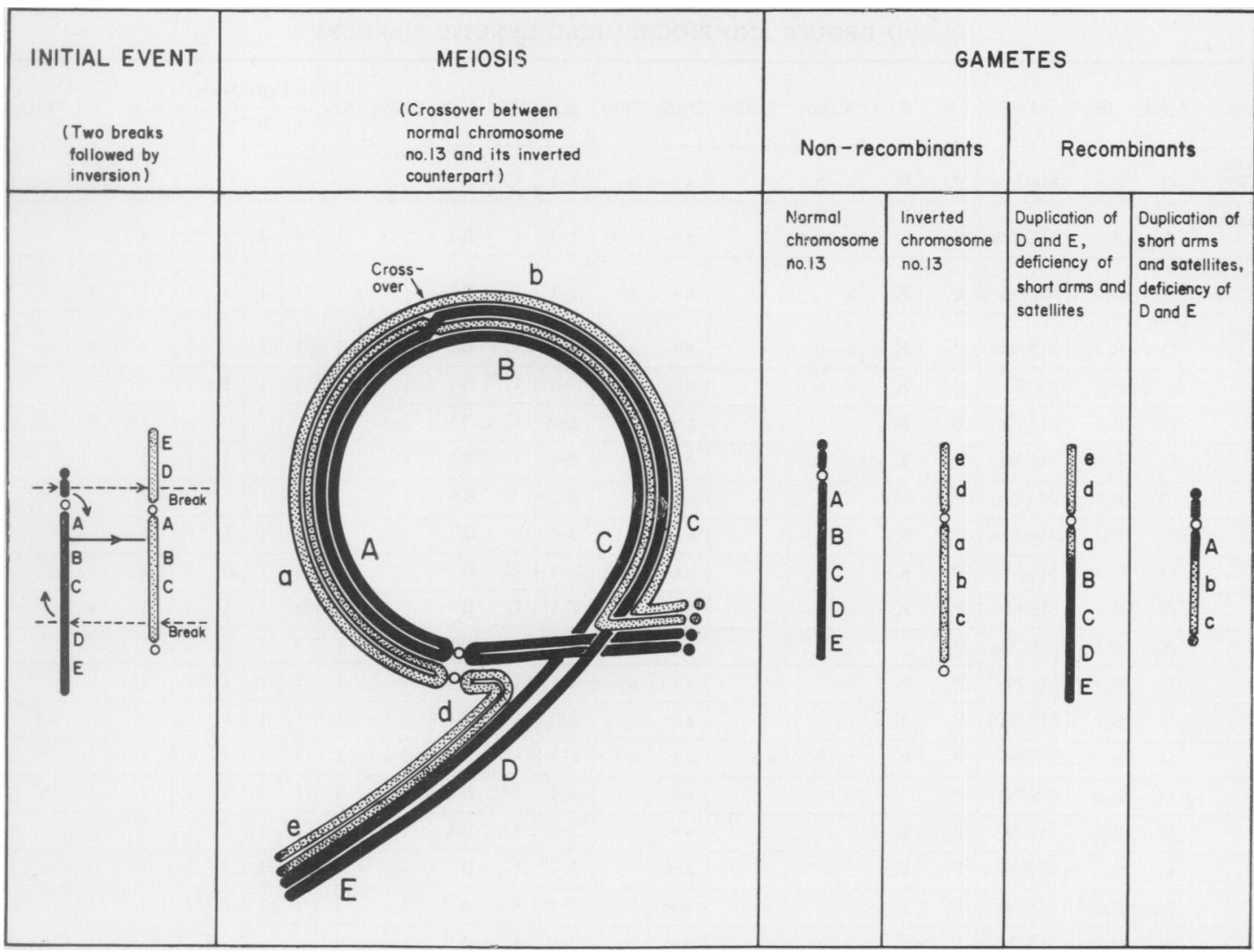

Fig. 7. Diagram showing the initial events leading to an inversion of chromosome No. 13, meiosis in an inversion heterozygote and the types of gametes formed after single cross-over within the meiotic loop.

and deficiency of short arms and satellites; (4) a probable abortion due to duplication of short arms and satellites of chromosome No. 13 and deficiency on the distal half of the long arm.

Like Jacobs et al (1969/1970) we found a high proportion of carriers in the family presented here, since 14 family members were carriers and 16 had a normal karyotype in good agreement with the expected ratio.

Large satellites were found on one of the Dgroup chromosomes of several individuals. This feature was present both in members with normal karyotypes (V.11, V.3, V.4), carriers (III.3, IV.5), and in the karyotype of one congenitally abnormal member (IV.14). This D chromosome which had a large short arm with prominent satellites was identified as No. 15 by its fluorescence in III. 3 and III.4. This was interpreted as a normal variant.

Clinical Discussion. The congenital abnormalities that were found in our 3 patients are listed in Table I; it was assumed that case 3 also had the same chromosome abnormality. The chief abnormalities consist of various peculiar cranofacial features, genital abnormalities, polydactyly and other abnormalities of the extremities, accelerated growth in early life, and mental retardation.

Parrington and Edwards (1971) described a patient with duplication deficiency of a $D_{1}$ chrosome due to a pericentric inversion. This patient turned out to have most of the clinical features that have been described in patients with trisomy 13: cleft palate, hare lip, eye defect, polydactyly, cardiac malformations, severe mental retardation, seizures, and death at an early age (Smith et al, 1963). Our patients had some of the anomalies that have been described in patients with this syndrome, as ear malformations, polydactyly, capillary haemangioma of the forehead and neck, renal abnormalities, cryptorchidism, and mental retardation. The mental deficiency of the 2 patients who are alive is however much less severe than in most of the 
patients with trisomy 13 and besides they have been in good health. The 3 rd patient who died at $5 \frac{1}{2}$ months of age probably had a heart defect.

Of course many of the clinical signs manifested by our patients have appeared in patients with other chromosomal abnormalities or in clinical syndromes of mental retardation.

Tall stature is known to occur in patients with an extra $\mathrm{Y}$ chromosome, but has not been described in other chromosomal abnormalities, which usually show dwarfism. Accelerated growth was manifested in 2 of our patients (case 1 and case 3). In the patient that is alive (case 1) this seems to be confined to infancy and early childhood since she is now close to normal stature. Accelerated growth has also been observed in patients with cerebral gigantism Sotos et al (1964) but our patients do not otherwise resemble these and no chromosomal abnormalities have been reported in this syndrome.

The possibility that some of the deceased members of the family under study might have had congenital abnormalities has been explored. IV.8 has already been described (case 3 ) as being affected, probably with the same chromosomal abnormality. II.2 died at 2 months of age, II.4 was stillborn, II. 6 died at 9 months, II. 8 died at 1 year, II. 11 died at 6 months, and IV.15 died at 3 months; according to information from the family none of these were malformed in any way. IV.28 died as the result of an accident.

The patients that have been presented here all have very similar congenital abnormalities although some of these are quite minimal. These 3 children certainly resemble each other much more than their own sibs and parents. It is therefore suggested that they may constitute a new syndrome associated with a specific chromosomal abnormality.

\section{Summary}

A family is presented in which 3 members had similar abnormalities, the 2 surviving members having an abnormal karyotype. Mitotic studies using labelling and fluorescent staining, and meiotic studies on one carrier, were consistent with a pericentric inversion of chromosome 13.

We are grateful to the family members for their understanding and cooperation. We thank Sigurður Sigurðsson MD and Friðrik Friðriksson MD for their assistance. We are indebted to Professor H. Harris and Dr E. B. Robson for blood group and biochemical data. We thank Professor J. H. Edwards for critically reviewing our manuscript and Oddný Vilhjálmsdóttir for her secretarial assistance.

This work has been supported by the US Atomic Energy Commission, contract No. AT(30-1)-3548.

\section{REFERENCES}

Chandra, H. S. and Hungerford, D. A. (1963). An aberrant autosome (13-15) in a human female and her father, both apparently normal. Cytogenetics, 2, 34-41.

Cohen, M. M., Capraro, V. J., and Takagi, N. (1966/1967). Pericentric inversion in a group D chromosome (13-15) associated with amenorrhea and gonadal dysgenesis. Annals of Human Genetics, 30, 313-323.

Crandall, B. F. and Sparkes, R. S. (1970). Pericentric inversion of a number 15 chromosome in nine members of one family. Cytogenetics, 9, 307-316.

Edwards, J. H. (1962). Chromosome analysis from capillary blood. Cytogenetics, 1, 90-96.

Jacobs, P. A., Brunton, M., Frackiewicz, A., Newton, M., Cook, P. J. L., and Robson, E. B. (1969/1970). Studies on a family with three cytogenetic markers. Annals of Human Genetics, 33, 325-336.

McDermott, A. (1966/1967). Human meiosis; the occurrence of interlocked bivalents in a normal male. Annals of Human Genetics, 30, 163-165.

Mikkelsen, M. (1971). Identification of $G$ group anomalies in Down's syndrome by quinacrine dihydrochloride fluorescence staining. Humangenetik, 12, 67-76.

Parrington, J. M. and Edwards, J. H. (1971). Patau's syndrome with $D_{1}$ duplication-deficiency derived from a maternal $D$ group pericentric inversion. Annals of Human Genetics, 35, 35-45.

Smith, D. W., Patau, K., Therman, E., Inhorn, S. L., and De Mars, R. I. (1963). The $D_{1}$ trisomy syndrome. Fournal of Pediatrics, 62, 326-341.

Sotos, J. F., Dodge, P. R., Muirhead, D., Crawford, J. D., and Talbot, N. B. (1964). Cerebral gigantism in childhood. A syndrome of excessively rapid growth with acromegalic features and a nonprogressive neurologic disorder. New England fournal of Medicine, 271, 109-116. 